\title{
Faculty Perspectives on Mis- and Disinformation across Disciplines
}

\section{Laura Saunders}

\begin{abstract}
Librarians, who have long promoted the criticality of information literacy, were quick to identify a role for themselves in confronting the challenges of mis/disinformation through library instruction. Nevertheless, little research has been done to examine discipline faculty's perspectives on mis/disinformation or the extent to which they are addressing the issue in their classrooms. This paper begins to address this gap in the literature through a nationwide study and follow-up interviews of faculty across disciplines to probe their perspectives on the challenges of mis/disinformation. Participants were asked about their views on mis/disinformation, whether and how they address mis/disinformation in their courses, and their perceptions of their students' ability to identify and evaluate mis/disinformation. The findings of this study have implications for academic librarians, especially liaison librarians with instructional responsibilities, and may be of interest to academic library directors and deans who oversee library instruction programs.
\end{abstract}

\section{Faculty Perspectives on Mis- and Disinformation across Disciplines}

Mis- and disinformation are not new issues, but sociopolitical events over the past several years have highlighted the challenges and threats they pose. Disinformation campaigns impacted the last two American presidential elections and the Brexit vote, as well as many other elections around the world. In the wake of the COVID-19 pandemic, mis/disinformation have influenced the public's compliance with health protocols such as mask-wearing, as well as their willingness to take a vaccine, leading the United Nations Secretary General to warn that "misinformation kills." ${ }^{1}$ In 2013, the World Economic Forum identified mis/disinformation as one of the top three global threats, ${ }^{2}$ following that in 2019 by noting that "among the most widespread and disruptive impacts of $\mathrm{AI}$ in recent years has been its role in the rise of "media echo chambers and fake news." ${ }^{3}$

Librarians, who have long promoted the criticality of information literacy, were quick to identify a role for themselves in confronting the challenges of mis/disinformation through library instruction. Library guides, blog posts, conference presentations, and publications related to mis/disinformation proliferated. Nevertheless, little research has been done to examine discipline faculty's perspectives on mis/disinformation, or the extent to which they are addressing the issue in their classrooms. Anecdotally at least, some academic librarians who

Laura Saunders is a Professor in the School of Library and Information Science at Simmons University; email: laura.saunders@simmons.edu. (C2022 Laura Saunders, Attribution-NonCommercial (https://creativecommons. org/licenses/by-nc/4.0/) CC BY-NC. 
typically depend upon faculty invitations to provide information literacy instruction have seen their efforts to address mis/disinformation on a wider scale somewhat stymied, as they have historically with broader information literacy initiatives. One possible reason for the perceived lack of interest in or attention to mis/disinformation among faculty may be a lack of consensus as to what mis/disinformation is and how it relates to and impacts their field or discipline, ${ }^{4}$ as is also the case with information literacy in general. ${ }^{5}$ As a result, some faculty may view these issues as generally important but only tangentially related to their discipline or specific teaching areas.

This paper begins to address this gap in the literature through a nationwide study and follow-up interviews of faculty across disciplines to probe their perspectives on the challenges of mis/disinformation. Participants were asked about their views on mis/disinformation, whether and how they address mis/disinformation in their courses, and their perceptions of their students' ability to identify and evaluate mis/disinformation. The findings of this study have implications for academic librarians, especially liaison librarians with instructional responsibilities, and may be of interest to academic library directors and deans who oversee library instruction programs.

\section{Literature Review}

Although the terms mis- and disinformation are sometimes used interchangeably, along with the related term "fake news," they are not exactly synonymous. First Draft News, a leading research outlet, defines misinformation as "information that is false, but not created with the intention of causing harm," while disinformation is "false and deliberately created to harm a person, social group, organization or country." ${ }^{6}$ Fake news could be understood as a type of disinformation, or "false, often sensational, information disseminated under the guise of news reporting." ${ }^{7}$ However, some feel that overuse and politicization have "rendered the term meaningless. All sorts of things-misinformation, spin, conspiracy theories, mistakes, and reporting that people just don't like-have been rolled into it." 8 This study relied on the definitions outlined by First Draft News.

The literature on mis- and disinformation, even just within the field of library and information science, is vast, and it is beyond the scope of this paper to provide a comprehensive review. Rather, the review provides a high-level overview and focuses on issues relevant to instruction related to the evaluation of mis- and disinformation, especially in an academic library setting.

\section{Overview}

The challenges posed by mis/disinformation are real and pervasive. Inaccurate information, whether shared with the intention to deceive or not, can influence people's opinions and decisions in ways that impact their well-being and that of others, and the effect can be long-term. In fact, when initially exposed to mis/disinformation, people often continue to believe the inaccurate information even when presented with new facts or retractions, a phenomenon known as the continued influence effect. ${ }^{9}$ When people are repeatedly exposed to the same inaccurate information, the likelihood of their perceiving the information as accurate increases, even if the information is labeled as inaccurate from the beginning. ${ }^{10}$ The persistence of mis/disinformation is compounded by cognitive biases, which lead people to seek out and encourage them to believe information that reinforces their existing worldview. ${ }^{11}$ Importantly, mis/disinformation has serious and inequitable social impacts. The false information campaigns often target vulnerable 
individuals and communities and have been used to spread fear and hate, occasionally leading to violence that disproportionately impacts marginalized communities and individuals. ${ }^{12}$

These challenges are exacerbated by the fact that people generally have trouble evaluating information and distinguishing between accurate and inaccurate information. According to a Pew Research poll, 64 percent of Americans believe that fake news is causing confusion about basic facts. ${ }^{13}$ Further, the study notes that, while Americans are fairly confident in their ability to detect misinformation, nearly one quarter admit that they have intentionally or unintentionally shared fake news stories. In a study of more than 7,000 students, researchers at Stanford reported that "in every case, at every level, we were taken aback by students' lack of preparation" and concluded that "young people's ability to reason about information on the Internet can be summed up in one word: bleak." 14 Their findings align with previous research showing that people tend to rely on superficial criteria when evaluating websites, including the site design, usability, and the page's position in the list of search results. People rarely check the "about us" pages or the credentials of the author or check to see if the site includes contact information. ${ }^{15}$ A later study showed that both college students and historians were more likely than professional fact-checkers to be deceived by misinformation, in part because they tended to rely on clues within the text, rather than exploring outside texts to verify the information presented. ${ }^{16}$

\section{Information Literacy Instruction}

Information literacy and related areas such as news and media literacy, with their focus on evaluation of information, seem a natural fit for challenging mis/disinformation, and academic librarians were quick to stake a role for themselves. ${ }^{17}$ Indeed, a web search shows hundreds of research guides, tutorials, infographics, and other resources created by academic librarians to guide students in identifying mis/disinformation. Questions have been raised regarding the extent to which information literacy instruction can insulate people against the impacts of mis/disinformation, ${ }^{18}$ especially when the focus of such instruction is on checklist-style and task-oriented criteria. ${ }^{19}$ Importantly, however, psychologists suggest that better critical thinking and reasoning skills can lead to better evaluation of mis/disinformation, ${ }^{20}$ and some research has shown at least modest gains in evaluation of information with instructional intervention. ${ }^{21}$

As librarians and educators begin to shift their instructional focus from process-oriented tasks to critical thinking, ${ }^{22}$ it is worth considering the debate as to whether competencies such as critical thinking and information literacy encompass a generic set of skills and dispositions that are applied across contexts, or whether they should be understood within the disciplines in which they are being implemented. While these debates are ongoing, some educators assert that either or both concepts should be understood within a discipline context. For instance, Moore argues that there are differences in how critical thinking is understood in disciplines like philosophy, history, and literature that are lost in a generic approach. ${ }^{23}$ Similarly, based on an extensive literature review, Weiner agrees that critical thinking is discipline-dependent, although he suggests that information literacy is generic. ${ }^{24}$ Other articles and studies, however, have suggested that information literacy, too, might be understood and applied differently across disciplines, ${ }^{25}$ leading to suggestions and models for tailoring library instruction to various disciplines. ${ }^{26}$

Mis/disinformation, perhaps due to the explosive popularity of and scrutiny into "fake news" over the past several years, is often discussed more in terms of news media and social media. As such, examples of mis/disinformation are often relatively popular sociopolitical 
issues such as national elections and the COVID-19 pandemic. However, it is important to recognize that issues of mis/disinformation impact every field and subject area. Certainly, health and science are widely recognized as fields impacted by mis/disinformation, with climate change and COVID-19 being clear examples. The spread of mis/disinformation has also impacted people's understandings of the risks and treatments of various types of cancer, ${ }^{27}$ tobacco and vaping safety, ${ }^{28}$ vaccines, ${ }^{29}$ and even the rollout of the $5 \mathrm{G}$ network. ${ }^{30}$ Mis/ disinformation campaigns have also impacted the business and financial worlds. The Warsaw Institute identifies a number of potential economic motivations for spreading disinformation, ${ }^{31}$ while The Washington Post reported on disinformation campaigns against corporations like Starbucks, Coca-Cola, and Costco. ${ }^{32}$ Hampton $^{33}$ and Ostherr ${ }^{34}$ argue for the role of the humanities in teaching the kind of close reading and critical text analysis needed for identifying mis/disinformation.

Given that mis/disinformation impacts can be found across all disciplines, and that the reasoning skills associated with competencies like critical thinking and information literacy are critical to identifying mis/disinformation, it stands to reason that conceptualizations of and approaches to mis/disinformation might vary across disciplines as they seem to do for information literacy and critical thinking. However, few studies have explored this question. One exception is Weiss et al., ${ }^{35}$ who surveyed 400 California State University faculty across 58 departments to explore how they define fake news as well as their attitudes toward it. While a clear majority of respondents agreed that fake news was important to them, the researchers found that definitions of and attitudes toward mis/disinformation, or "fake news," varied substantially across departments and disciplines. For example, they found that English faculty were most concerned with how readers received fake news as well as the motivations behind its creation, but were less concerned with how the news was disseminated, whereas Biology and Health Sciences faculty were concerned with means of dissemination. Faculty also varied by discipline with regard to the approaches they favored for analyzing and identifying fake news, with faculty in the College of Education emphasizing in-depth research, while those in the College of Humanities focused on content type.

Based on the survey responses, the researchers asserted that faculty across disciplines exhibited "differing views on how information is used, what makes an informed reader, and how to verify resources." 36 They inferred that these differences could be tied to differences in the fields themselves, leading them to contest that "faculty definitions of fake news and the strategies to verify information are bound by discipline-specific norms." ${ }^{37}$ Weiss et al. note that "not much is currently in publication about the attitudes of university faculty on fake news," and, while they explored faculty's conceptualizations and attitudes toward the issue, they did not examine how these definitions and attitudes impacted their instruction, if at all. This paper builds on the work of Weiss et al. and begins to address the gap in the literature by further exploring disciplinary differences with regard to faculty attitudes toward mis/disinformation, as well as whether and how they incorporate issues of mis/disinformation in their teaching.

\section{Methods}

The purpose of this study was to explore faculty attitudes toward mis/disinformation and examine how they are responding to challenges of mis/disinformation in their classrooms, as well as to probe whether differences exist across disciplines in faculty attitudes toward and engagement with mis/disinformation. Specifically, this study explored the following questions: 
- Are faculty across disciplines concerned about the spread of mis/disinformation? If so, what challenges and threats do they perceive?

- Are faculty incorporating issues of mis/disinformation into their teaching? If so, what strategies do they use, and what are their perceptions of their students' proficiencies in identifying and evaluating mis/disinformation?

- Are there differences across disciplines in faculty responses to these questions?

Because the aim of this study was to establish a broad baseline of faculty responses across disciplines, a large sample size was required. Surveys, which tend to be more quantitative in nature and can be distributed electronically and taken at the respondents' leisure, are better suited to larger sample sizes than more qualitative methods such as focus groups or interviews. However, the quantitative nature of surveys also limits the depth of responses and the ability to probe answers. As such, a mixed-methods approach of a nationwide survey with follow-up interviews was selected to capture both breadth and depth.

The population for the study was faculty teaching in public or private nonprofit colleges and universities across disciplines in the United States. To draw a random sample, a research assistant downloaded a data set of all 4-year degree-granting private and public nonprofit colleges and universities from the IPEDs database, resulting in a list of 1,834 institutions. The (rand) function in Excel was used to assign a random number to each institution. The institutions were then sorted by number, and the first 500 institutions were selected for the study. The research assistant reviewed the resultant list and removed institutions that exclusively offered religious degrees or otherwise did not meet the criteria of four-year degree-granting public or private colleges and universities. Ultimately, a random sample of 429 institutions was achieved.

For each institution, the research assistant visited the faculty directory on the institution's home page and used two random numbers generated from random.org to select two faculty members from the list. In cases where the list was broken down by discipline, two numbers from random.org were used to select two departments, and then the normal procedure was used to select faculty members from those departments. During this stage, institutions with no publicly accessible directory and institutions that did not include an email in the directory were eliminated from the sample. Ultimately, 724 faculty members were identified for the survey.

The survey was developed in and disseminated through Qualtrics (see appendix). An initial invitation to take the survey was sent out on September 10, 2020, with three follow-up emails sent to nonrespondents during the following six weeks. The survey was closed on October 21. The first block of questions asked participants to rate their level of agreement with a series of statements about mis/disinformation, including the extent to which they were concerned about its spread both in general and within their field, the efficacy or appropriateness of various methods of combating mis/disinformation, and their opinion about whether mis/disinformation should be addressed in higher education. Next, respondents were asked if they had addressed problems of mis/disinformation in any of the classes they taught during the past year. If they answered no, they were asked to indicate any reasons why they had not addressed the topic. If they answered yes, they were asked to indicate any methods they used to address the topic, and whether they had ever worked with a librarian on the topic. If they answered yes to working with a librarian, they were asked to indicate any methods they used in that collaboration. All respondents were then asked to rate their perception of their students' proficiency in various competencies related to news literacy. The content portion of 
the survey ended with an open-ended question asking if respondents had anything to add. The final block of questions gathered demographic information, including the respondents' field or subject area, position, years in the field, and type of institution. Upon completing the survey, respondents were asked if they would be willing to participate in a follow-up interview. If they answered yes, they were directed to a new site to provide their contact information.

The interviews consisted of several open-ended questions asking participants to share their thoughts about mis/disinformation both in general and in the field, whether they addressed mis/disinformation in their courses and, if so, how. The interviews were all conducted by Zoom at a time convenient for the participant, and ranged from about 45 minutes to one hour. All the interviews were recorded. Once the interview was completed, the autogenerated transcript was downloaded and any personally identifying information was scrubbed, then the recordings were deleted.

The quantitative information from the surveys was analyzed using descriptive and inferential statistics. Numbers and percentages were gathered for each answer to get an overall view of faculty perspectives in general and across disciplines. The crosstabs function in Qualtrics was used to conduct chi-squared tests $(p=0.05)$ for statistically significant differences in responses by discipline. Specifically, crosstabs were used to test for differences by discipline in faculty's levels of agreement with the general statements about mis/disinformation, whether they reported addressing mis/disinformation in their courses, what methods they used if they did address mis/disinformation, or what reasons they offered if they did not. Tests were also run to look for differences by discipline in faculty's ratings of student proficiencies in news literacy skills.

Ultimately, only six respondents agreed to be interviewed; likewise, very few participants responded to the open-ended survey questions. While these are too few responses to truly analyze for patterns and cannot be used to draw comparisons across disciplines, they still provide some useful context when analyzed in light of the quantitative survey results. Each interview transcript was reviewed multiple times, and broad ideas and concepts were noted. For instance, comments about misinformation related to COVID-19, vaccinations, or mask-wearing were grouped together as health concerns. These qualitative responses were also reviewed in light of the survey responses to see how they confirm or contrast with the quantitative survey results.

\section{Findings}

An initial set of 724 surveys was distributed. After accounting for 36 emails that bounced back, the survey was sent to a total of 688 faculty members. The surveyed garnered 86 responses, for a response rate of 12.5 percent. This response rate is low, so care must be taken in generalizing results. However, the results still provide some broad insight into faculty attitudes toward mis/disinformation, the extent to which these faculty members are addressing mis/disinformation in their courses, and their perspectives on their students' news literacy proficiencies.

Survey participants came from a range of subject areas, experience levels, and positions. There was a wide distribution of faculty across fields and disciplines, from a low of only two respondents in Social Work and History $(2.5 \%)$ to a high of 13 in the social sciences $(16.3 \%)$. Eight respondents $(10 \%)$ identified as Other. Fields and disciplines for these respondents included religion, philosophy, engineering, and urban planning. Figure 1 shows the breakdown of respondents by discipline. The vast majority of respondents (58\%) were tenured 
faculty, followed by untenured faculty on the tenure track (25\%), and full-time contract faculty $(11.3 \%)$. Only 2.5 percent of respondents identified as adjuncts. Respondents also skewed fairly heavily toward more years of teaching experience, with 45 percent indicating that they had been teaching at the college level for more than 20 years. Roughly equivalent numbers of respondents reported teaching for $5-10$ years $(18.8 \%)$ and $11-15$ years $(17.5 \%)$. The remaining respondents had been teaching for $16-20$ years $(11.3 \%)$ or fewer than 5 years $(7.5 \%)$. The majority of respondents came from private, not-for-profit institutions $(57.5 \%)$, followed by public institutions (38.8\%). Although the focus for the study was on public and private not-forprofit institutions, 3 respondents (3.8\%) identified as being from private for-profit institutions.

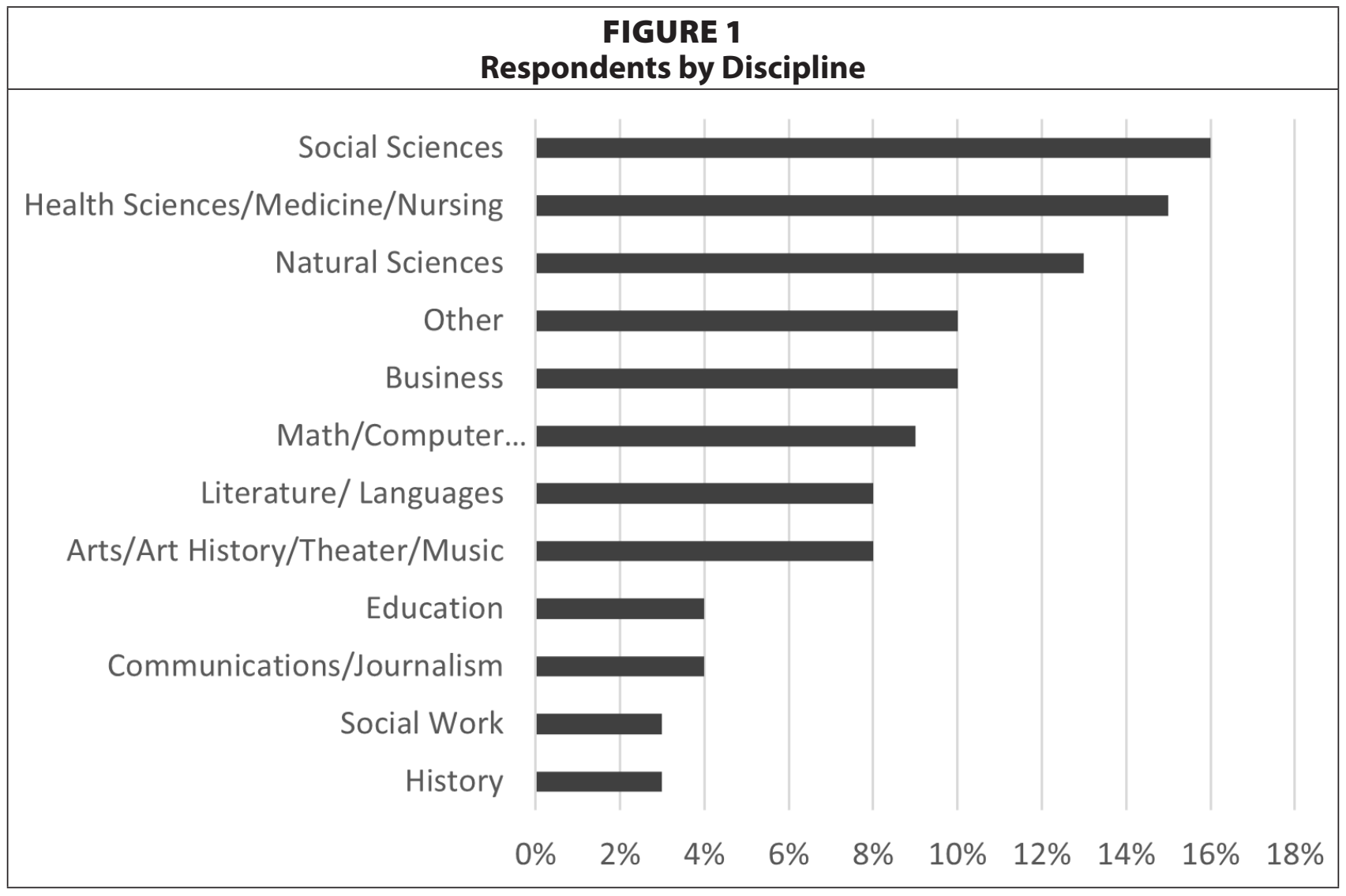

\section{Opinions about Mis/Disinformation Impacts and Solutions}

The first matrix of questions asked respondents to rate their level of agreement with several statements about the impacts of and potential responses to mis/disinformation. While there was some general agreement, there was also substantial variance in the answers, especially for certain statements. The majority of respondents expressed some concern about the spread of mis/disinformation in general. Specifically, 94 percent of respondents strongly agreed or agreed that they are concerned about the spread of mis/disinformation on social media, and 93 percent strongly agreed or agreed that they are concerned about the spread of mis/disinformation in news media. However, only 46 percent of respondents strongly agreed or agreed that they are concerned about the spread of mis/disinformation in their field/discipline, while 29 percent strongly disagreed or disagreed with that statement. There were no statistically significant differences for this question, but the responses did vary widely by field. For instance, 73 percent of respondents in the health sciences and 60 percent of respondents in the 
natural sciences strongly agreed or agreed that they are concerned about the spread of mis/ disinformation in their field, while 100 percent of respondents in communications and journalism, 43 percent of respondents in math, computer science, and technology, and 38 percent of respondents in business strongly disagreed or disagreed with that statement.

Several other statements showed relatively strong consensus. For instance, 89 percent of respondents strongly agreed or agreed that instruction in news literacy competencies is important in combating mis/disinformation, with most (72\%) strongly agreeing, and 85 percent strongly agreed or agreed that the spread of mis/disinformation is a threat to democracy. Similarly, 88 percent strongly agreed or agreed that the spread of mis/disinformation impacts students' ability to find reliable and trustworthy information. Despite strong agreement that news literacy skills are important and students' ability to evaluate information is being impacted by mis/disinformation, respondents were somewhat more varied in their opinions about how to address news literacy. In total, 75 percent strongly agreed or agreed that instructors in higher education have a responsibility to teach news literacy skills, but less than half of those $(42 \%)$ strongly agreed with the statement. Further, 14 percent strongly disagreed or disagreed that instructors in higher education have such a responsibility.

Respondents were similarly split in their opinions about other responses to mis/disinformation. While two-thirds (66\%) strongly agreed or agreed that human-driven fact-checking sources are important in combating mis/disinformation, 22 percent strongly disagreed or disagreed with that statement. Just under half of respondents (49\%) strongly agreed or agreed that the spread of mis/disinformation on social media should be regulated, while nearly one-third $(32 \%)$ strongly disagreed or disagreed. Just over one-third (39\%) strongly agreed or agreed that artificial intelligence solutions such as better algorithms are important for combating mis/ disinformation, 20 percent strongly disagreed or disagreed, and a plurality (41\%) are neutral. Figure 2 shows the full breakdown of responses to these statements.

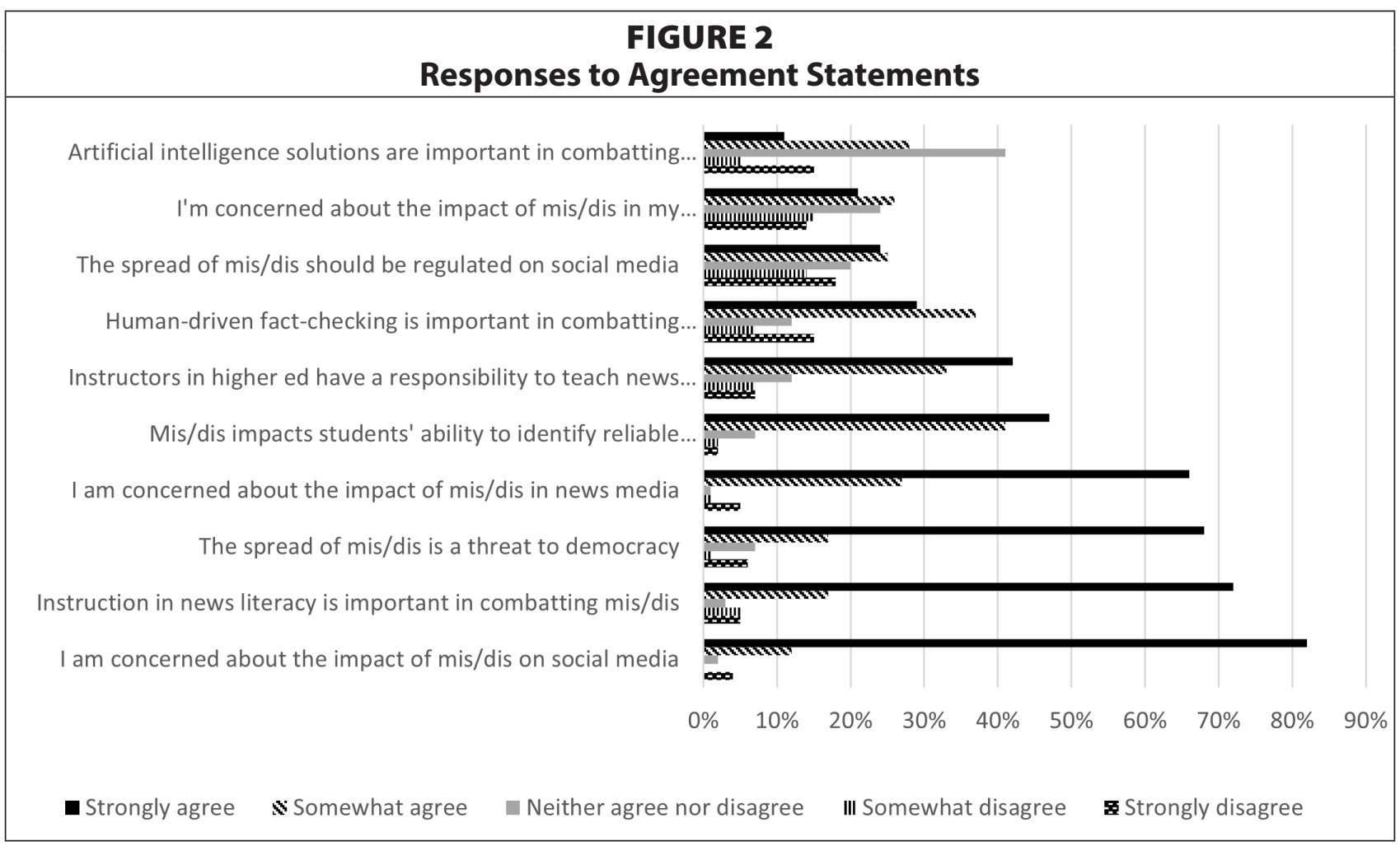




\section{Differences across Disciplines}

The study explored whether differences exist across disciplines in faculty attitudes toward and responses to mis/disinformation. The crosstab function in Qualtrics was used to run chisquared tests of the responses to agreement statements by discipline. Some questions showed consistency across disciplines. The vast majority of respondents across disciplines strongly agreed or agreed that they are concerned about the spread of mis/disinformation on social media. Concern about the impact of mis/disinformation on students' ability to find reliable and trustworthy sources was similarly consistent across disciplines, with a majority agreeing that this is a concern. Likewise, a majority in each discipline agreed that instruction in news literacy is important in combating mis/disinformation, although, interestingly, 33 percent of respondents in both literature/languages and art/art history/theater strongly disagreed with that statement. Not a single respondent from any other discipline strongly disagreed that news literacy is important.

For other questions, there was some substantial variance in responses by discipline. While the vast majority of respondents report being concerned about the spread of mis/disinformation in the news media, a full 100 percent of respondents in the natural sciences, history, education, and social work strongly agreed with that statement, while respondents in other fields were somewhat more varied. In math, computer science, and technology, for instance, 43 percent strongly agree and 29 percent agree with that statement, but another 29 percent strongly disagree. Likewise, 83 percent of respondents in literature and languages strongly agree, but 17 percent strongly disagree. Respondents also varied across disciplines with regard to their concern about the spread of mis/disinformation in their field. For instance, faculty in health sciences showed the most concern, with 73 percent strongly or somewhat agreeing they are concerned about the spread of mis/disinformation in their field, followed by two-thirds $(66 \%)$ in literature/languages and art/art history/theater. Some fields showed more moderate concern, with 60 percent in natural science, 54 percent of respondents in the social sciences, 50

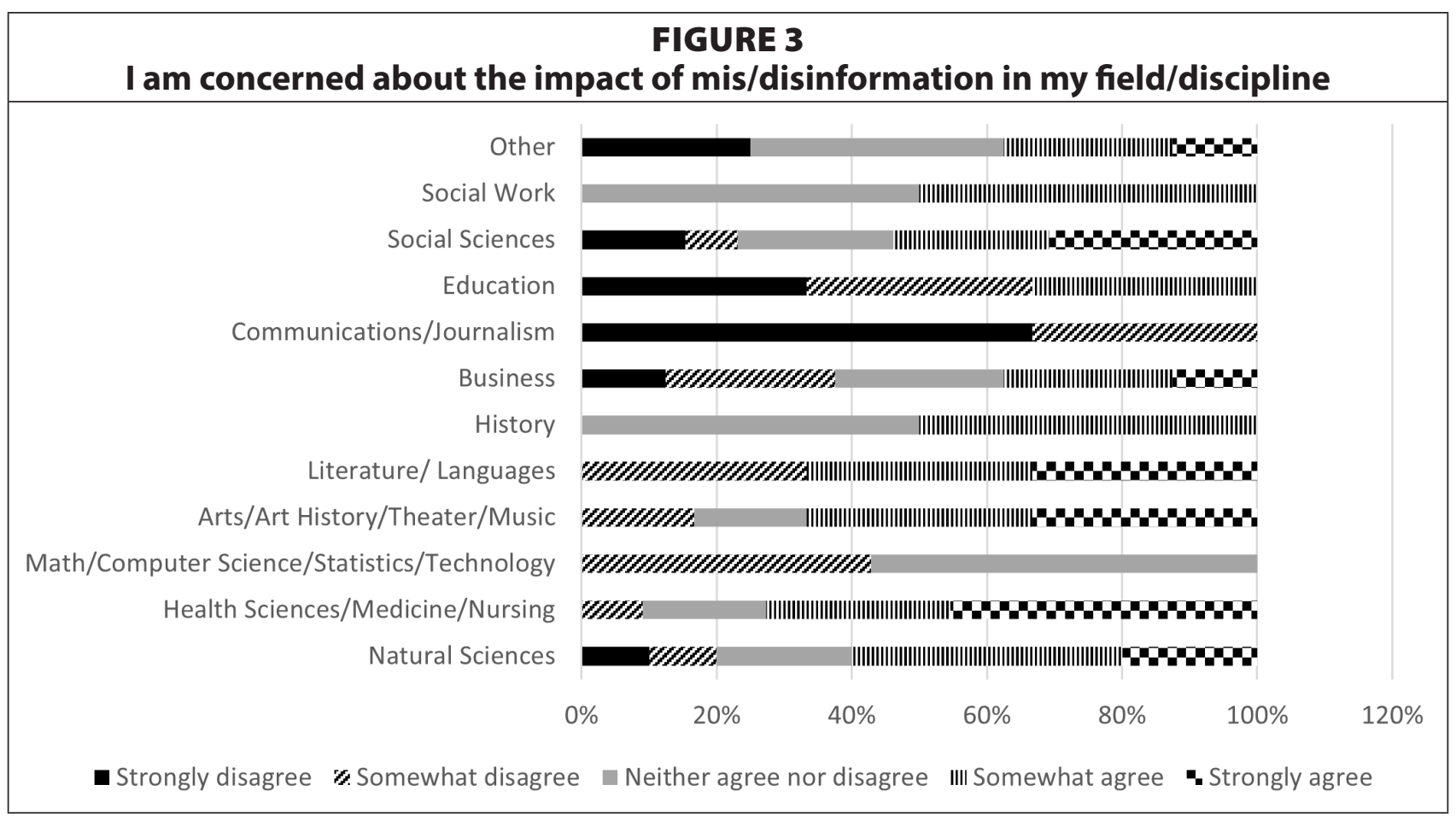


percent in social work, and 50 percent in history strongly or somewhat agreeing. Conversely, 100 percent of respondents in communications and journalism and 66 percent in education strongly or somewhat disagreed with that statement. Forty-two percent of respondents in math/ computer science/technology somewhat disagreed that they are concerned by the spread of mis/disinformation in their field, and 57 percent are neutral. Business faculty showed the most variance within a field, with 37 percent strongly or somewhat agreeing, 37 percent strongly or somewhat disagreeing, and 25 percent neutral. Figure 3 shows the full range of responses to the statement "I am concerned about the impact of mis/disinformation in my field" by discipline.

While faculty were fairly consistent across disciplines with regard to the importance of news literacy instruction as an intervention for mis/disinformation, they were more varied in response to other interventions. Fifty-eight percent of health sciences faculty strongly or somewhat agreed that AI interventions are important, closely followed by 57 percent of math/ computer science/technology faculty and 50 percent of social work faculty. Other disciplines were more skeptical of AI solutions, with 50 percent of art/art history/theater faculty strongly disagreeing or disagreeing that they are important, followed by 33 percent of literature/languages and communications/journalist faculty. A similar split across disciplines surfaced with regard to human-driven fact-checkers as an intervention, with 100 percent of social work and history faculty strongly or somewhat agreeing this is an important intervention, followed by 78 percent of social sciences faculty, 75 percent of faculty in business, 70 percent in natural sciences, 67 percent in health sciences, and 66 percent in literature/languages, communication/ journalism, and education. On the other hand, 67 percent of faculty in art/art history/theater and 43 percent in math/computer science/technology strongly or somewhat disagreed that human-driven fact-checkers are important interventions. Figures 4 and 5 show the breakdown by discipline of these two statements.

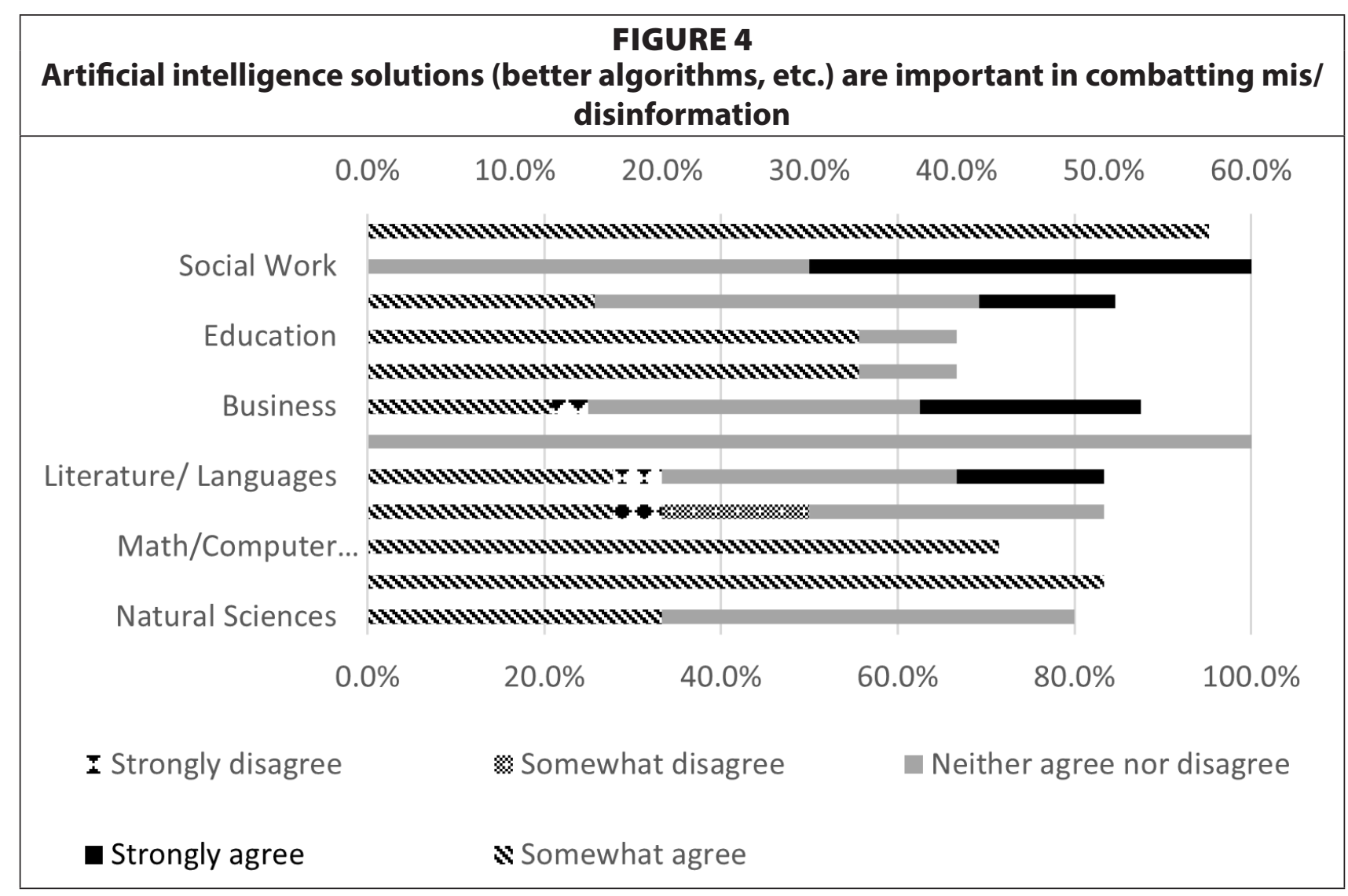




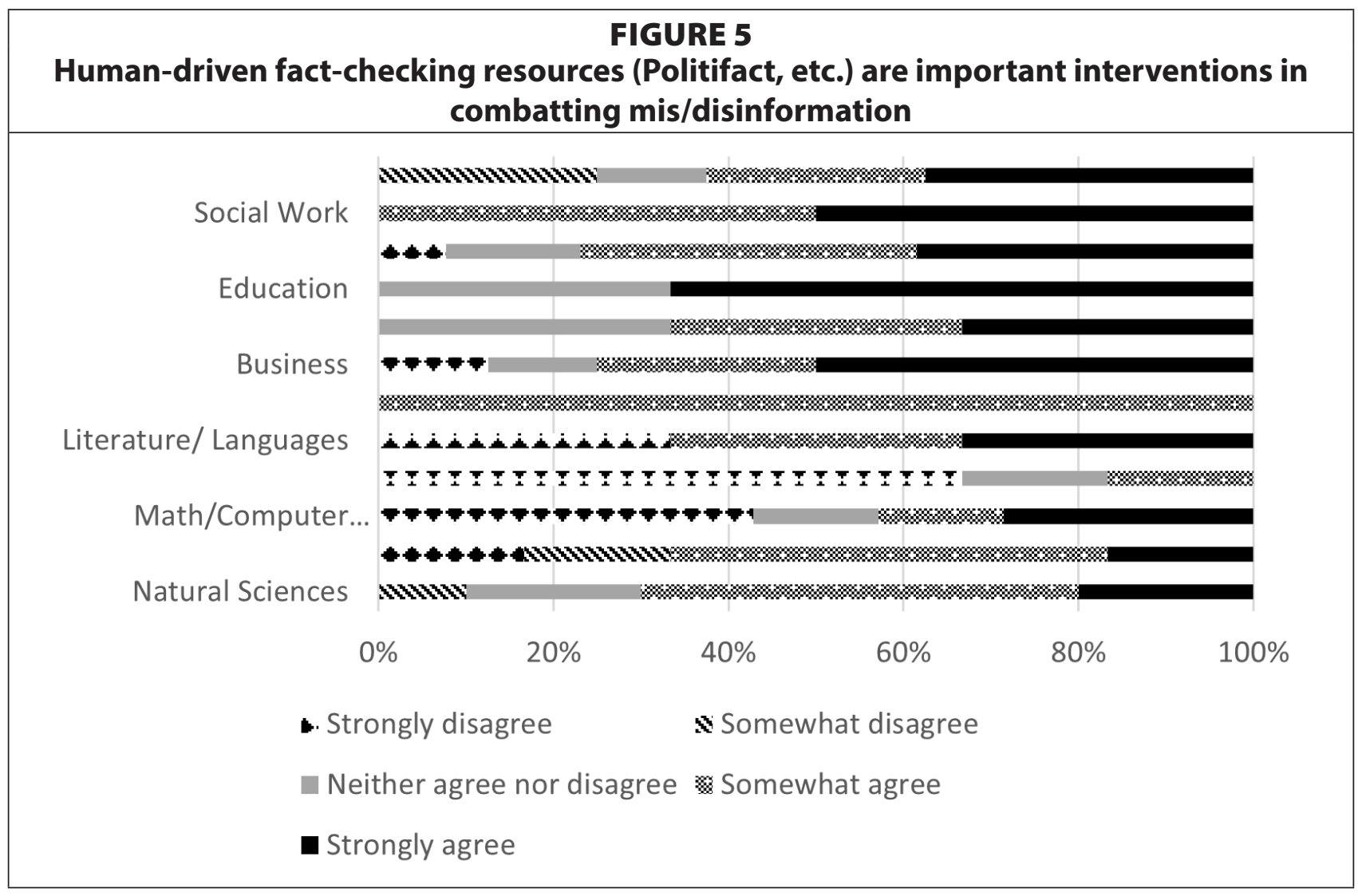

Despite some substantial variance across disciplines in responses to these statements, chi-squared tests revealed only one statistically significant difference, for agreement with the statement "the spread of mis/disinformation is a threat to democracy" $(p=0.028)$. While a strong majority across disciplines strongly or somewhat agreed with this statement, faculty in some disciplines were more skeptical. For instance, 20 percent of faculty in health sciences strongly disagreed and 20 percent were neutral; one-third of communications and journalist faculty somewhat disagreed with the statement; 17 percent of art/art history/theater and literature/language faculty strongly disagreed; and 17 percent of art/art history/theater and math/computer science/technology faculty were neutral. Figure 6 shows the breakdown of responses to this question.

\section{Addressing Mis/Disinformation in the Classroom}

A majority of respondents $(67 \%)$ reported that they had addressed issues of mis/disinformation in their classrooms over the past year. However, 16 respondents skipped this question, and several disciplines were not represented in the findings for this question. Requiring students to cite trustworthy sources in assignments is the most popular method for addressing mis/ disinformation (28\%), followed by requiring students to argue positions using trustworthy sources $(20 \%)$, and incorporating news literacy instruction (19\%). Fewer respondents reported assessing students' ability to evaluate mis/disinformation (10\%), including using assignments requiring students to identify mis/disinformation (9\%). Respondents were also given an opportunity to write in other methods they use to address mis/disinformation and six participants did so, usually describing specific activities or lessons. For instance, one participant spends time teaching about peer review, another has students "practice turning reasonable 


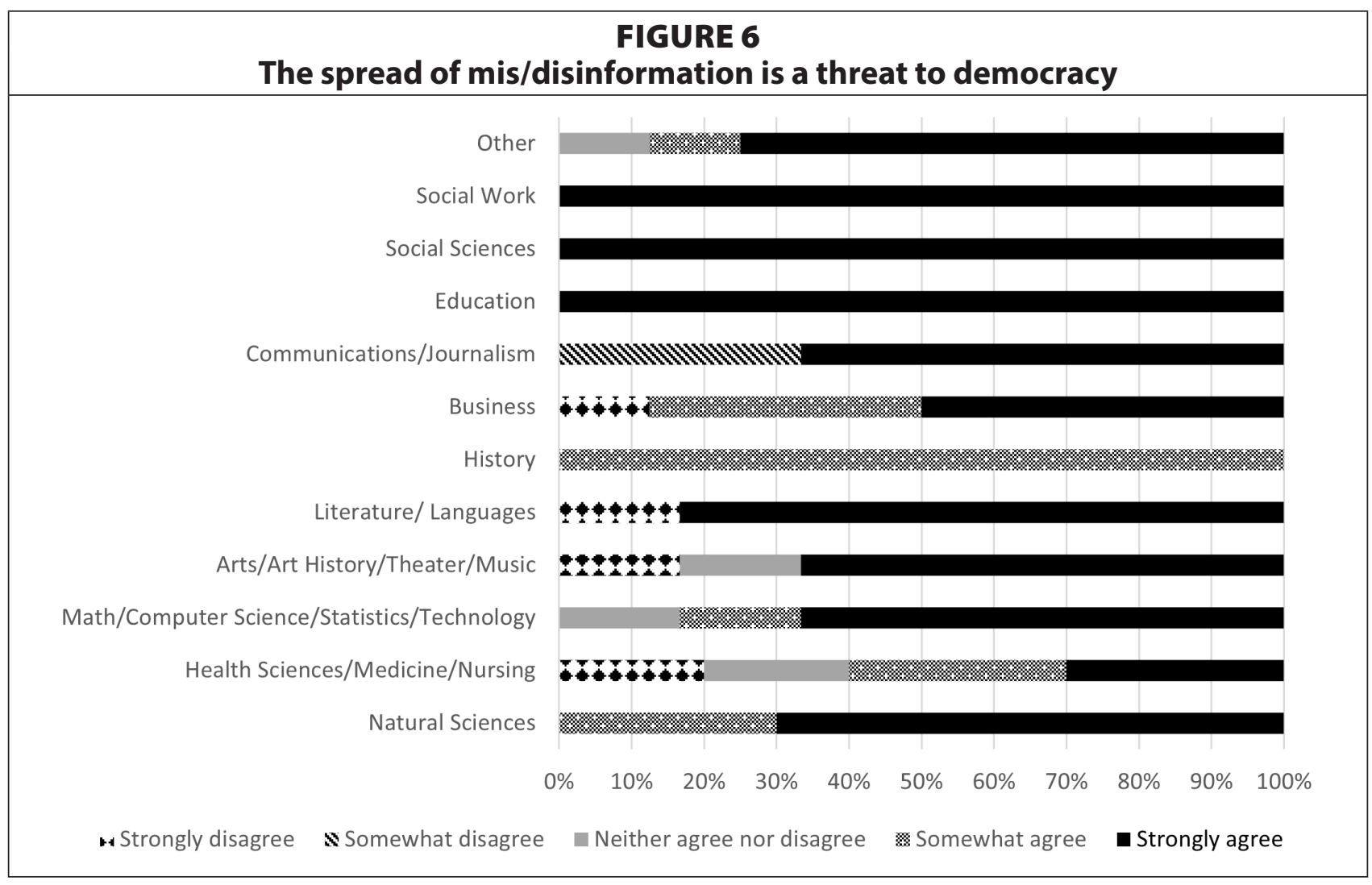

information into mis/disinformation propaganda pieces," while another says they "explained how statistics about Covid are being misrepresented to make it seem worse than it really is."

Faculty across disciplines varied somewhat with regard to whether they addressed mis/ disinformation in their classes, but the difference was not statistically significant. Faculty in the social sciences were the most likely to address mis/disinformation in class $(92 \%)$, followed by the natural sciences ( $80 \%)$, and health sciences and literature/languages (67\% each). On the other hand, there were some statistically significant differences in the methods faculty used to teach about mis/disinformation across the disciplines. Specifically, there was a statistically significant difference in whether faculty require students to cite trustworthy information in assignments $(p=0.03)$. In most disciplines, 100 percent of faculty report using this requirement, but only 67 percent of education faculty, 63 percent of faculty in the natural sciences, and 33 percent of faculty in math/computer science/technology report using this requirement. There was also a statistically significant difference with regard to requiring students to argue a position using trustworthy information $(p=0.04)$. One hundred percent of faculty in literature/ languages and communications/journalism require students to do this, followed by 75 percent of faculty in social sciences and business. Faculty in the natural sciences and math/computer science/technology were the least likely to report this requirement (38\% and 33\% respectively).

Only 28 faculty responded that they have not addressed mis/disinformation in their courses, and the number within each discipline was low. These respondents were asked to indicate why they have not addressed the topic. Interestingly, the highest percentage of respondents $(48 \%)$ indicated they do not teach mis/disinformation in their classes because the concepts are not relevant to their field/discipline. This was also the only choice to show a statistically significant difference $(p=0.03)$. Somewhat startlingly, 100 percent of respondents 
to this question in health sciences, math/computer science/technology, and literature indicated that mis/disinformation is not relevant to their field. Conversely, no faculty in the natural or social sciences indicated that these concepts were irrelevant to their field. Five respondents submitted other reasons for not addressing mis/disinformation, with one respondent saying faculty could use "more focused training on pedagogy in this issue," and another stating that "any such content would be ideologically skewed, usually to the left."

\section{Working with a Librarian}

A majority of respondents (79\%) have not worked with a librarian to address news literacy or mis/disinformation in their courses. The responses varied by discipline, with literature/ language faculty being most likely to have worked with a librarian (75\% worked with a librarian) and social work, education, and math/computer science/technology the least likely (100\% had not worked with a librarian). However, there was no statistically significant difference for this question.

Those faculty who had worked with a librarian reported using a variety of methods in doing so. Having a librarian guest-lecture in one or more classes and referring students to librarians for research assistance were the most popular methods at 31 percent each, followed by pointing students to research guides from the library (19\%) and consulting with a librarian to design activities or assignments $(14 \%)$. Only 6 percent say they consult with a librarian when assessing student work in this area.

\section{Student Proficiencies}

Participants were asked to rate their undergraduate students' new literacy proficiencies on a 5-point scale from very proficient to not at all proficient. Virtually across the board, participants' ratings clustered around the middle of the scale, with students generally being rated as somewhat proficient on each skill. Students received the highest ratings for evaluating information for relevance, with 33 percent of respondents rating them very proficient or proficient in this skill, followed by selecting appropriate information to complete a research

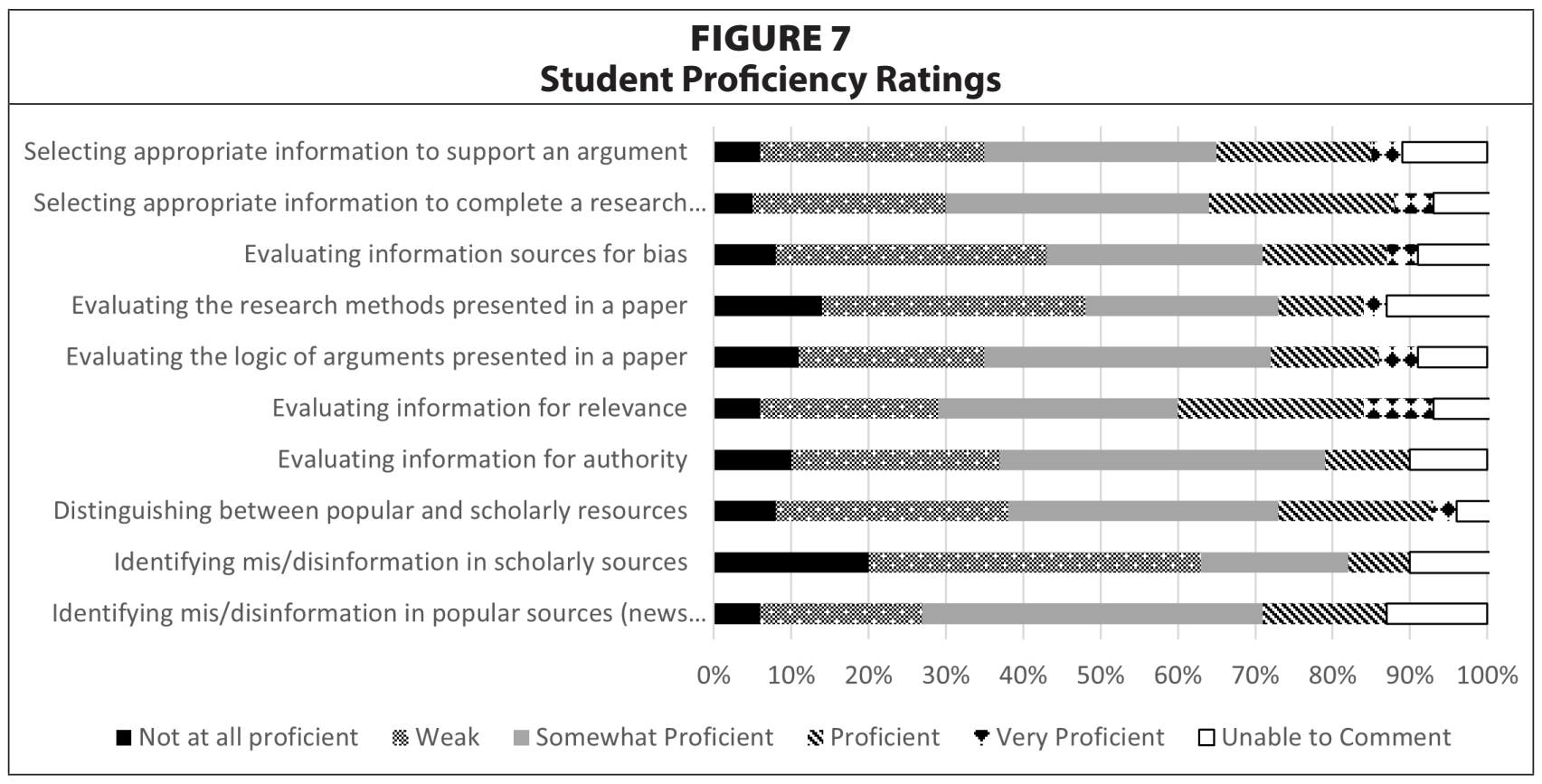


assignment at 29 percent. Students received the lowest ratings for identifying mis/disinformation in scholarly sources, with 63 percent of respondents rating them as not at all proficient or weak in this area, followed by evaluating the research methods presented in a paper $(48 \%$ not at all proficient or weak), and evaluating information sources for bias ( $43 \%$ not at all proficient or weak). Interestingly, there were no statistically significant differences across disciplines in ratings of student proficiencies. Figure 7 shows the breakdown of responses for this question.

\section{Interviews}

Only six participants agreed to be interviewed. Because the number of interviewees was so low, their comments cannot be taken as representative of their fields, or used to make generalizations. However, their input does help to contextualize some of the survey findings and offer some additional insight into how some faculty are approaching these issues. All of the interviewees indicated that they were concerned about the spread of mis/disinformation in general, and they identified various causes. The interviewees broadly identified their fields as biology, business/accounting, creative writing, history, psychology, and social work. Several interviewees lamented that people do not take the time to vet their sources, and some also pointed to the issue of confirmation bias, or the tendency for people to accept information that reinforces their existing worldview even in the face of contradictory evidence. As one interviewee put it, "people used to go listen to the news to hear the news and now they go listen for validation." Some of them also pointed to the growing partisan divide and the difficulty that poses for having civil disagreements.

Despite shared concerns about mis/disinformation, the interviewees varied as to whether they had incorporated instruction on these topics in their courses. The accounting, biology, creative writing, and history professors were not currently addressing this topic. However, the biology, history, and creative writing instructors discussed the importance of teaching critical thinking and analysis skills; they just did not frame it within the areas of mis/disinformation. For instance, the biology professor noted that he spends substantial time on scientific literacy topics, including distinguishing between primary and secondary literature and assessing research paper methodologies, skills that could be valuable for evaluating mis/disinformation as well. This participant also intimated that he might like to do more on the topic but did not necessarily feel confident about "how to kind of put an explanatory lecture together to talk about that." This sentiment seemed to echo a response to the open-ended survey question indicating a need for more pedagogical training on teaching about mis/disinformation. The creative writing professor indicated that he had taught a course on conspiracy theories in the past and, given its relevance to the current moment, was interested in teaching it again. The accounting professor suggested that issues of mis/disinformation were less relevant to his field, stating that within the business school "we tend to stick to teaching the topics and not anything else around it."

The psychology and social work professors both addressed issues of mis/disinformation directly in their courses and talked about specific lessons or approaches they had designed. The psychology professor had one class doing a course project on fake news, involving field research, while the social work professor posed questions to her classes on hot button topics like climate change and vaccines; she had students find and evaluate resources to take a position on the topics. The social work professor noted that she discusses how to evaluate web resources as well as scholarly resources, and the psychology professor discussed the need to 
assess peer-reviewed sources rather than assuming that they are necessarily accurate because they have been peer-reviewed.

Five of the six interviewees said that they had worked with a librarian in their courses in the past, although not necessarily on mis/disinformation topics. Only the accounting professor had never worked with a librarian. Of the five who had worked with a librarian, all had invited librarians to speak in their classes, and the social work librarian had consulted with a librarian to design a tutorial for her classes. In general, the participants focused on the librarians' role in helping students search databases and find information as opposed to evaluating information or other higher-level, critical thinking skills. All spoke very highly of the librarians with whom they had worked, often mentioning them by name, referencing conversations outside of the classroom, and commenting on their expertise.

The interviewees were cautiously positive in their assessment of student skills with mis/ disinformation, saying students "have a lot of common sense," a "gut ability to see something that is outrageous and know that it is," and that they "already know how to assess whether something is true, or whether something is 'trueish'." The psychology and social work professors were a bit more granular in their analysis of their students' skills. The psychology professor said, "for the most part they are doing a good job with what we're asking them to do," but she also observed that her students tend to think that other people are more likely to be fooled by mis/disinformation, but generally believe they will not be, a phenomenon known as the third-party effect. She also noted that her students seem to have a harder time analyzing issues to which they are more emotionally connected, as well as analyzing and understanding positions that conflict with their own beliefs. Likewise, the social work professor discussed specific examples of students who would ignore evidence and discount reliable sources that contradicted their positions. Both the psychology and social work professors noted that they see a difference between upper- and lowerclassmen, with the older students having more developed skills. The psychology professor specifically mentioned attempting to scaffold these skills.

One unanticipated finding from the interviews was a concern expressed by three interviewees about addressing topics that might be viewed as partisan or political. Without prompting, these participants self-identified at different points on the political spectrum from progressive/liberal to conservative, but each expressed similar concerns about how discussions on political topics might be received by students. For instance, one participant mentioned a colleague who is upfront about their political stance with their students. In contrast, this participant stated, "I don't take a position. I don't espouse my personal views I believe that's inappropriate. Again I've been paid to educate my students in [the field]. Full stop." He went on to say that, when he brings examples into the classroom, he is "very careful to keep them nonbiased." Another participant noted that he introduces various theoretical perspectives, such as critical race, queer theory, and postcolonialism, as lenses for interpreting course content, but he said he is always clear with his students that he is presenting these theories as part of the scholarly conversation, not advocating for any of them. This interviewee expressed some discomfort with taking this approach but felt it was necessary "on the off chance that somebody gets the idea that, you know, I'm like, you know, trying to indoctrinate - that's supposedly - allegedly that's what we do on college campuses." A third participant shared some concern about students seeing them as "somebody who's trying to push a political agenda." 
It was unclear whether these concerns were directly tied to or arising from conversations of mis/disinformation. However, given how politically charged many of these issues are, and the fact that the three interviewees who brought up these concerns were also not currently engaging with mis/disinformation topics in class (though at least one had in the past), it is possible that concerns about being perceived as having a political agenda could be hindering some instructors from addressing mis/disinformation issues in the classroom.

\section{Discussion}

The findings of this study show that faculty across disciplines are concerned about the impact of mis/disinformation in general, and they believe their students are not especially proficient in the news literacy skills necessary to identify and evaluate mis/disinformation. Although most faculty think news literacy skills are important, they vary in the extent to which they are addressing issues of mis/disinformation in their classrooms, and their reasons for not addressing the topic vary. Of those who are addressing mis/disinformation, few report working with librarians. Aside from news literacy skills, faculty vary with regard to which solutions they believe to be most important for combating mis/disinformation. The differences across disciplines were a focal point of this study, and, whether statistically significant or not, they provide some context for what is happening in the classroom.

At least half of faculty across disciplines believe news literacy skills are important in combating mis/disinformation, and most believe instructors in higher education have some responsibility to teach these skills. Importantly, although there was variance, there was no statistically significant difference across disciplines as to whether faculty addressed mis/ disinformation topics in their classrooms. Math/computer science/technology and art/art history were the only fields with more than half of instructors reporting that they do not address these topics. Business was split in half, with 50 percent reporting they do address mis/ disinformation, and 50 percent saying they do not. Most other fields were substantially higher, with 92 percent of social sciences faculty saying they teach about mis/disinformation. This finding suggests that, while students in majors or disciplines like math, computer science, and art might be somewhat less likely to receive explicit instruction in mis/disinformation, all students have at least some chance of receiving such instruction. Those faculty who are addressing mis/disinformation use a range of methods to do so, including explicit instruction on the topic, various assignments that require students to identify and use trustworthy sources and, in some cases, assessment of student skill in this area.

The fact that faculty across the disciplines are concerned about mis/disinformation and about their students' abilities in this area, and that just over two-thirds are addressing the topic in their classes, could have implications for academic librarians. Virtually all of the interviewees acknowledged librarians to be experts in this area, suggesting there may be a role for librarians to offer support in teaching to this topic. Indeed, those faculty who have worked with a librarian on this topic often drew on the kinds of guides, tutorials, and tools that librarians have been creating, in addition to inviting librarians to speak in their classes. Nevertheless, few instructors report working directly with librarians on instruction for mis/disinformation. It is not clear from the survey itself why so few instructors are working with librarians, but time could be a factor. At least one interviewee noted that he had had librarians come into his classes in the past, but that he tends to cover the material himself now. 
Another reason might be a lack of awareness about the kind of support librarians can offer. Virtually all of the interviewees who reported working with a librarian described the librarian's role as helping students to search databases, find peer-reviewed articles, and distinguish between popular and scholarly sources, all of which are more task- or process-based skills, as opposed to the high-order critical thinking skills needed to evaluate information and its sources. Given that there is some evidence that faculty believe students' search skills are at least adequate while concerns about their ability to evaluate information persist, ${ }^{39}$ faculty may feel little impetus to invite librarians to their classes if they anticipate the instruction will focus mostly on searching. Librarians may have to engage in outreach to raise awareness about the range of topics and skills they can address, especially with regard to identifying and evaluating mis/disinformation.

It could also be important for librarians to better understand why some faculty are not addressing mis/disinformation in their classrooms. Although no respondents said the topic was unimportant, faculty gave several reasons for not addressing this topic. Many participants indicated that they do not have time to address this content, and many believed it should be addressed elsewhere in the curriculum. Given that most faculty do think topics associated with mis/disinformation and news literacy skills are important, and most want to see them addressed somewhere within the curriculum, there might be some opportunities for librarians within general education and extracurricular programs to support news literacy instruction. Assuming that news literacy, like information literacy, is often relegated to general education and lower-level courses, ${ }^{40}$ librarians might begin by working with faculty who coordinate those courses to provide resources and support. They could also explore offering workshops, research appointments, and other support services focused on mis/disinformation outside of the classroom to reduce the amount of class time necessary.

However, as with information literacy, these general education and extracurricular approaches to news literacy are necessarily limited and likely to be inadequate, as they typically address generic rather than discipline-specific skills and do not allow for scaffolding skill development over time. Such an approach also belies the importance faculty supposedly put on these skills. Interestingly, there was a statistically significant difference for discipline faculty who contend that the content was not relevant to their discipline. Although the numbers were small, 100 percent of faculty in health sciences/medicine, math/computer science/technology, and literature/languages who said they did not address mis/disinformation in their classrooms said that the content was not relevant to their discipline.

It might be conceivable that issues of mis/disinformation, which are generally focused on factual disputes, might not seem relevant to literature courses focusing on fiction, poetry, or creative writing. However, as the creative writing professor noted in the interview, these courses do teach close reading and critical thinking skills, which are directly relevant to information and news literacy. It is much harder to imagine how faculty in health sciences or math and computer science could argue that these topics are not relevant to their disciplines, given the amount of attention focused on mis/disinformation related to public health issues like COVID-19 and vaccines, and on the role of technology and issues like algorithmic bias, filter bubbles, and echo chambers in facilitating the spread of mis/disinformation. The nature of this survey, as well as the low response rate, make it challenging to infer why some faculty would view mis/disinformation as irrelevant to their field. Perhaps some courses are truly so narrowly focused that discussions of mis/disinformation would not be relevant although, 
again, it is hard to imagine any area of health sciences where that would be true. Regardless, librarians should be aware that, in some cases, and perhaps especially in some disciplines, faculty might not be receptive to outreach focused on mis/disinformation. Future research might probe this area.

Interestingly, two participants expressed some uneasiness with their own ability to teach about mis/disinformation. In response to the open-ended survey question, one participant who identified as a history instructor wrote that "as instructors we probably could use more focused training in pedagogy on this issue." That sentiment was echoed in the interview portion of the study by the biology professor. Although he was confident in his own fact-checking and evaluative abilities, he noted that he did not feel that he had the expertise to develop an in-depth lecture or lesson on mis/disinformation, stating "that's kind of where I feel the weakest." Although these are only two participants' thoughts, it is possible that they reflect a wider swath of instructors, and this could signal an opportunity for librarians to provide professional development and pedagogical training for these instructors. Librarians could present history and theory of mis/disinformation, discuss tools and techniques for identifying and evaluating mis/disinformation with an emphasis on critical thinking, and share activities and learning objects that could be integrated into courses. Because the ratio of librarians to students generally makes it impossible for librarians to embed into or guest-lecture in more than a few courses each semester, this sort of "train the trainer" approach might increase the number of students exposed to instruction on mis/disinformation by allowing faculty to incorporate the instruction into their lessons themselves. As such, this approach could also alleviate the need to take up class time with one-shot sessions. Perhaps such training could also help some faculty see the connections between issues of mis/disinformation and their discipline.

One of the more interesting results of this study is that, despite some substantial variance in responses, there were very few statistically significant differences among the disciplines. This finding stands somewhat in contrast to Weiss et al., who made a greater case for disciplinary differences with regard to mis/disinformation. Notably, however, Weiss's study focused more narrowly on definitions, whereas this study took a somewhat broader view. However, even when this study found variance, it was often as much within disciplines as across disciplines. And, interestingly, those findings were sometimes contradictory. For instance, although 50 percent of literature/language faculty strongly or somewhat disagreed that they have a responsibility to teach news literacy skills, 67 percent indicated that they have addressed issues of mis/disinformation in their classes. This discrepancy could reflect the fact that literature and language teachers often bear responsibility for teaching in general education courses, which might be more likely to focus on current events and/or to have learning outcomes related to information and related literacies. Whatever the reason, overall findings suggest that there is substantial interest in mis/disinformation topics and in teaching news literacy skills somewhere within the curriculum, and that resistance or hesitancy to teach those topics might be more a function of individual faculty's sense of the topic and time pressures than an inherently discipline-based difference.

\section{Conclusion}

This study demonstrates that faculty across disciplines are broadly concerned about the impacts of mis/disinformation, but they vary in the extent to which they are incorporating mis/ disinformation topics into their courses, and few are working with librarians on the topic. 
While the variable lack of attention to mis/disinformation and low levels of collaboration with librarians may be somewhat discouraging, the study also points to opportunities for librarians. The findings also reveal that most faculty agree that news literacy skills are important. They largely believe that their students' news and information literacy skills need some improvement, especially with regard to evaluating information, and many feel some responsibility for teaching these skills. Interviewees were strongly supportive of their librarians, acknowledging their expertise. Librarians could build on these good feelings and general interest in the topic to promote greater attention to mis/disinformation in the curriculum. Through outreach efforts, librarians could raise awareness about the topic and about the range of news literacy skills they can support, with an emphasis on evaluation and critical thinking over search skills. They might also focus on "train the trainer" approaches to provide faculty with the knowledge and pedagogical background to feel more confident in addressing these topics themselves. 


\section{APPENDIX. Faculty Perceptions of Mis/Disinformation and News Literacy}

Your response to the following survey is greatly appreciated. I am a faculty member at Simmons University School of Library and Information Science currently studying misinformation and news literacy in undergraduate programs. You have been randomly selected as a teaching faculty member whose primary teaching responsibility is at the undergraduate level. Your responses to this brief survey will assist other faculty members, librarians, and library directors plan for curricula to improve student learning in this important competency.

The survey should take about 10-15 minutes to complete. During the survey you may choose to stop participation at any time.

You will not be asked to provide any personally identifiable information. At the end of the survey, you will be asked if you are willing to be contacted for a brief follow-up interview. If you are interested, you will be redirected to a separate form, so your name will not be attached to your survey responses.

If you have any questions about this survey, you can contact Laura Saunders at Simmons College: laura.saunders@simmons.edu. You can also contact the Human Protections Administrator in the Simmons College Office of Sponsored Programs at 617-521-2415 with questions about the study ethics.

Thank you very much, in advance, for sharing your experience and ideas!

Laura Saunders, PhD

Assistant Professor

Simmons College Graduate School of Library and Information Science

\section{START SURVEY}

\section{This survey uses the following definitions:}

Misinformation: Inaccurate information shared by accident

Disinformation: Inaccurate information shared on purpose to mislead/deceive

News literacy: "critical-thinking skills for analyzing and judging the reliability of news and information, differentiating among facts, opinions and assertions in the media we consume, create and distribute." - schooljournalism.org

1. Please rate your level of agreement with the following statements (strongly agree to strongly disagree):

a. I am concerned about the impact of mis/disinformation in news media

b. I am concerned about the impact of mis/disinformation on social media

c. I am concerned about the impact of mis/disinformation in my field/discipline

d. The spread of mis/disinformation impacts my students' ability to identify reliable and trustworthy information

e. The spread of mis/disinformation should be regulated on social media

f. The spread of mis/disinformation should not be regulated

g. News literacy is an important skill

h. Instruction in news literacy competencies is important in combatting mis/disinformation 
i. Artificial intelligence solutions (better algorithms and the like) are important in combating mis/disinformation

j. Human-driven fact-checking resources (Politifact and others) are important interventions in combating mis/disinformation

k. Instructors in higher education have a responsibility to teach news literacy skills

2. I have addressed the problems of mis/disinformation in one or more classes I have taught over the past year

a. Yes/no (If yes, go to question 4; if no, go to question 3)

3. What are some of the reasons you do not address mis/disinformation in your classes [check all that apply]?

a. I do not have time to add this content

b. This content is not relevant to my field/discipline

c. This content is not important

d. This content is important but should be addressed elsewhere in the curriculum

e. Students have already learned these concepts

f. Other [please specify]

[Go to Question 8]

4. How have you addressed issues of mis/disinformation in any of your courses [check all that apply]?

a. I include assignments or activities that require students to identify mis/disinformation in one or more classes that I teach

b. I incorporated instruction on news literacy skills (finding and evaluating information, identifying mis/disinformation) in one or more of my courses during the last year

c. I require students to cite trustworthy information in their assignments

d. I require students to argue positions using trustworthy information

e. I assess student ability to identify mis/disinformation in one or more classes that I teach

f. I assess student ability to evaluate mis/disinformation in one or more classes that I teach

g. Other [please specify]

5. Thinking about the undergraduate students you have taught during the last year, please rate your students' proficiency in the following areas (very proficient to not at all proficient):

a. Identifying mis/disinformation in popular sources (news media, social media, and other popular sources)

b. Identifying mis/disinformation in scholarly sources

c. Distinguishing between popular and scholarly resources

d. Searching for information

e. Evaluating information for authority

f. Evaluating information for relevance

g. Evaluating information for trustworthiness

h. Evaluating the arguments or methods presented in a paper

i. Evaluating information sources for bias

j. Selecting appropriate information to complete a research assignment 
k. Selecting appropriate information to support an argument

6. Have you ever worked with a librarian in addressing mis/disinformation or news literacy in any of your courses?

a. Yes/no (If yes, go to question 7; if no, go to question 8)

7. What are some of the ways that you have worked with a librarian [check all that apply]?

a. A librarian has guest-lectured in one or more class sessions

b. I consulted with a librarian when designing activities or assignments with news literacy or mis/disinformation components

c. I consulted with a librarian when assessing student work

d. I refer students to the librarians for assistance with research

e. I point students to a guide/handout from the library

f. Other [please specify]

8. Is there anything else that you would like to add?

9. In what field do you primarily teach?

10. What is your position?

a. Tenure-track faculty/untenured

b. Tenured faculty

c. Contract faculty/full-time

d. Adjunct/part-time

e. Teaching assistant

f. Other, please specify

11. How many years have you been teaching at the college level?

a. $>5$

b. $6-10$

c. $11-15$

d. $16-20$

e. $20+$

12. Which best describes your institution?
a. Public
b. Private, not-for-profit
c. Private, for-profit

13. What is your institution's basic Carnegie Classification?

a. Doctoral University

b. Master's College or University

c. Baccalaureate College

d. Baccalaureate/Associate's College

e. Associate's College

f. Special Focus

\section{Notes}

1. Antonio Guterres, "Statement by the Secretary-General on the 1 Millionth Death from the COVID-19 Pandemic," United Nations Secretary-General (September 28, 2020), https://www.un.org/sg/en/content/sg/statement/2020-09-28/statement-the-secretary-general-the-1-millionth-death-the-covid-19-pandemic-scroll-downfor-french-and-spanish.

2. Lee Howell, "Global Risks 2013," http://reports.weforum.org/global-risks-2013/title-page/ [accessed 7 
February 2021].

3. World Economic Forum, “The Global Risks Report 2019, 14th Edition,” http://www3.weforum.org/docs/ WEF_Global_Risks_Report_2019.pdf [accessed 7 February 2021].

4. Andrew P. Weiss et al., "Surveying Fake News: Assessing University Faculty's Fragmented Definition of Fake News and Its Impact on Teaching Critical Thinking," International Journal for Educational Integrity 16, no. 1 (February 1, 2020): 1-30, https://doi.org/10.1007/s40979-019-0049-x.

5. Laura Saunders, "Faculty Perspectives on Information Literacy as a Student Learning Outcome," Journal of Academic Librarianship 38, no. 4 (July 1, 2012): 226-36, https://doi.org/10.1016/j.acalib.2012.06.001.

6. Claire Wardle and Hossein Derakhshan, "Information Disorder: Toward an Interdisciplinary Framework for Research and Policy-Making: Strasbourg, Council of Europe," Shorenstein Center (October 31, 2017), https:// shorensteincenter.org/information-disorder-framework-for-research-and-policymaking/ [accessed 7 February 2021].

7. Collins Dictionary, "Fake News" (2018), https://www.collinsdictionary.com/us/dictionary/english/fakenews [accessed 7 February 2021].

8. Mike Wendling, "The (Almost) Complete History of 'Fake News,'” BBC News: BBC Trending (January 22, 2018), www.bbc.com/news/blogs-trending-42724320.

9. Ullrich K.H. Ecker et al., "Correcting False Information in Memory: Manipulating the Strength of Misinformation Encoding and Its Retraction," Psychonomic Bulletin \& Review 18, no. 3 (June 1, 2011): 570-78, https:// doi.org/10.3758/s13423-011-0065-1.

10. Gordon Pennycook, Tyrone D. Cannon, and David G. Rand, "Prior Exposure Increases Perceived Accuracy of Fake News," Journal of Experimental Psychology: General 147, no. 12 (December 2018): 1865-80, https://doi. org/10.1037/xge0000465.supp (Supplemental).

11. Shahram Heshmat, “What Is Confirmation Bias?” Psychology Today (April 23, 2015), https://www.psychologytoday.com/us/blog/science-choice/201504/what-is-confirmation-bias [accessed 7 February 2021].

12. Chinmayi Arun, "On WhatsApp, Rumours, Lynchings, and the Indian Government," Economic and Political Weekly 45, no. 6 (Feb. 9, 2019), https://papers.ssrn.com/abstract3336127; Ashley Nerbovig, “'Truth Is Lost' as Michigan's Immigrant Communities Hit with Misinformation on Closed Platforms," Arab American News (November 28, 2020), https://search-ebscohost-com.ezproxy.simmons.edu/login.aspx?direct=true\&db=asn\&AN $=147254408 \&$ site $=$ eds-live \&scope $=$ site.

13. Michael Barthel, Amy Mitchell, and Jesse Holcomb, "Many Americans Believe Fake News Is Sowing Confusion," Pew Research Center, Journalism and Media (December 15, 2016), www.journalism.org/2016/12/15/ many-americans-believe-fake-news-is-sowing-confusion/.

14. Sam Wineburg et al., "Evaluating Information: The Cornerstone of Civic Online Reasoning," Stanford History Education Group: 4 (2016), http://purl.stanford.edu/fv751yt5934.

15. Eszter Hargittai et al., “Trust Online: Young Adults' Evaluation of Web Content," International Journal of Communication (19328036) 4 (March 2010): 468-94, https://search-ebscohost-com.ezproxy.simmons.edu/login.as px?direct=true\&db=ufh\&AN=51893348\&site=eds-live\&scope=site; Dirk Lewandowski, "Search Engine User Behaviour: How Can Users Be Guided to Quality Content?" Information Services \& Use 28, no. 3/4 (July 2008): 261-68, https://search-ebscohost-com.ezproxy.simmons.edu/login.aspx?direct=true\&db=buh\&AN=35821883\&s ite $=$ eds-live \&scope $=$ site.

16. Sam Wineburg and Sarah McGrew, "Lateral Reading and the Nature of Expertise: Reading Less and Learning More When Evaluating Digital Information," Stanford History Education Group (July 28, 2018), https:// stacks.stanford.edu/file/druid:yk133ht8603/Wineburg\%20McGrew_Lateral\%20Reading\%20and\%20the\%20Nature\%20of\%20Expertise.pdf.

17. Shellie Jeffries et al., "Says Who? Librarians Tackle Fake News," College \& Research Libraries News 78, no. 10 (November 2017): 538-45, https://doi.org/10.5860/crln.78.10.538; Shannon Najmabadi, "Information Literacy," Chronicle of Higher Education (March 3, 2017), https://search-ebscohost-com.ezproxy.simmons.edu/login. aspx?direct=true\&db=asn\&AN=121630434\&site=eds-live\&scope=site; Matthew C. Sullivan, "Libraries and Fake News: What's the Problem? What's the Plan?" Communications in Information Literacy 13, no. 1 (January 1, 2019): 91-113, https://search-ebscohost-com.ezproxy.simmons.edu/login.aspx?direct=true\&db=eric\&AN=EJ1227587\&s ite $=$ eds-live\&scope $=$ site.

18. David M.J. Lazer et al., “The Science of Fake News: Addressing Fake News Requires a Multidisciplinary Effort (Cover Story)," Science 359, no. 6380 (March 9, 2018): 1094-96, https://doi.org/10.1126/science.aao2998; M. Connor Sullivan, “Why Librarians Can't Fight Fake News," Journal of Librarianship and Information Science 51, no. 4 (December 1, 2019): 1146-56, https://doi.org/10.1177/0961000618764258.

19. Wineburg and McGrew, "Lateral Reading and the Nature of Expertise."

20. S. Mo Jones-Jang, Tara Mortensen, and Jingjing Liu, “Does Media Literacy Help Identification of Fake 
News? Information Literacy Helps, but Other Literacies Don't," American Behavioral Scientist 65, no. 2 (February 2021): 371-88, https://doi.org/10.1177/0002764219869406; Kirsten Weir, "Why We Fall for Fake News: Hijacked Thinking or Laziness?" American Psychological Association website (December 11, 2020), https://www.apa.org/ news/apa/2020/02/fake-news.d

21. Erica Weintraub Austin et al., "Processing of Sexual Media Messages Improves Due to Media Literacy Effects on Perceived Message Desirability," Mass Communication \& Society 18, no. 4 (July 2015): 399-421, https://doi.or g/10.1080/15205436.2014.1001909; Elisha Babad, Eyal Peer, and Renee Hobbs, "Media Literacy and Media Bias: Are Media Literacy Students Less Susceptible to Nonverbal Judgment Biases?" Psychology of Popular Media Culture 1, no. 2 (April 2012): 97-107, https://doi.org/10.1037/a0028181; Sarah McGrew et al., “Improving University Students' Web Savvy: An Intervention Study," British Journal of Educational Psychology 89, no. 3 (September 2019): 485-500, https://doi.org/10.1111/bjep.12279; Heather Brodie Perry, "Conflict of Interest in Scientific Research: Does Explicit Instruction Increase Undergraduate Knowledge and Recognition of Potential Conflict?" Order No. 27742156, Simmons College (2019), https://ezproxy.simmons.edu/login?url=https://www-proquest-com.ezproxy.simmons. edu/dissertations-theses/conflict-interest-scientific-research-does/docview/2385690798/se-2?accountid=13870.

22. Allison Faix and Amy Fyn, "Framing Fake News: Misinformation and the ACRL Framework," portal: Libraries \& the Academy 20, no. 3 (July 2020): 495-508, https://doi.org/10.1353/pla.2020.0027; Mandi Goodsett, "Assessing the Potential for Critical Thinking Instruction in Information Literacy Online Learning Objects Using Best Practices," Communications in Information Literacy 14, no. 2 (September 2020): 227-54, https://doi.org/10.15760/ comminfolit.2020.14.2.4; Jorge Revez and Luís Corujo, "Librarians against Fake News: A Systematic Literature Review of Library Practices (Jan. 2018-Sept. 2020)," Journal of Academic Librarianship 47, no. 2 (March 1, 2021), https://doi.org/10.1016/j.acalib.2020.102304; John M. Weiner, "Is There a Difference between Critical Thinking and Information Literacy? A Systematic Review 2000-2009," Journal of Information Literacy 5, no. 2 (December 2011): 81-92, https://doi.org/10.11645/5.2.1600.

23. Tim John Moore, "Critical Thinking and Disciplinary Thinking: A Continuing Debate," Higher Education Research and Development 30, no. 3 (January 1, 2011): 261-74, https://search-ebscohost-com.ezproxy.simmons.edu/ login.aspx?direct=true\&db=eric\&AN=EJ923820\&site=eds-live\&scope=site.

24. Weiner, "Is There a Difference between Critical Thinking and Information Literacy?"

25. Ann Grafstein, "A Discipline-Based Approach to Information Literacy," Journal of Academic Librarianship 28, no. 4 (July 2002): 197, https://doi.org/10.1016/S0099-1333(02)00283-5; Saunders, “Faculty Perspectives on Information Literacy as a Student Learning Outcome"; Lauri J. Vaughan, Sue Smith, and Meredith Cranston, "An Argument for Disciplinary Information Literacy," Knowledge Quest 44, no. 5 (May 1, 2016): 38, https://search-ebscohost-com. ezproxy.simmons.edu/login.aspx?direct=true\&db=edsgao\&AN=edsgcl.453286297\&site=eds-live\&scope=site.

26. Peggy Keeran and Michael Levine-Clark, Research Within the Disciplines: Foundations for Reference and Library Instruction, Second Edition (Lanham, MD: Rowman \& Littlefield Publishers, 2014), https://search-ebscohost-com. ezproxy.simmons.edu/login.aspx?direct=true\&db=nlebk\&AN=771867\&site=eds-live\&scope=site; Patrick Ragains and Kimberly Thornton, Information Literacy Instruction That Works: A Guide to Teaching by Discipline and Student Population, Second Edition (New York, NY: Neal-Schuman, 2013).

27. Eric R. Walsh-Buhi, "Social Media and Cancer Misinformation: Additional Platforms to Explore," American Journal of Public Health 110 (October 2, 2020): S292-93, https://doi.org/10.2105/AJPH.2020.305949; Tamar Wilner and Avery Holton, "Breast Cancer Prevention and Treatment: Misinformation on Pinterest, 2018," American Journal of Public Health 110 (October 2, 2020): S300-04, https://doi.org/10.2105/AJPH.2020.305812; Marco Zenone, Jeremy Snyder, and Timothy Caulfield, "Crowdfunding Cannabidiol (CBD) for Cancer: Hype and Misinformation on GoFundMe," American Journal of Public Health 110 (October 2, 2020): S294-99, https://doi.org/10.2105/ AJPH.2020.305768.

28. Dolores Albarracin et al., "Misleading Claims about Tobacco Products in YouTube Videos: Experimental Effects of Misinformation on Unhealthy Attitudes," Journal of Medical Internet Research 20, no. 6 (June 29, 2018): e229, https://doi.org/10.2196/jmir.9959; Andy S.L. Tan and Cabral A. Bigman, "Misinformation about Commercial Tobacco Products on Social Media-Implications and Research Opportunities for Reducing Tobacco-Related Health Disparities," American Journal of Public Health 110 (October 2, 2020): S281-83, https://doi.org/10.2105/ AJPH.2020.305910.

29. Carla Montuori Fernandes and Christina Montuori, "The Misinformation Network and Health at Risk: An Analysis of Fake News Included in 'The 10 Reasons Why You Shouldn't Vaccinate Your Child'," RECIIS 14, no. 2 (June 1, 2020), https://doi.org/10.29397/reciis.v\%vi\%i.1975; Amelia Jamison et al., "Adapting and Extending a Typology to Identify Vaccine Misinformation on Twitter," American Journal of Public Health 110 (October 2, 2020): S331-39, https://doi.org/10.2105/AJPH.2020.305940.

30. Russell Seekins, "Misinformation: 5G \& HEALTH: Conspiracy Theories Mutated during the Pandemic: Communicating the Facts Is a Shared Endeavour That Requires Mutually Reinforcing Activities," Intermedia 
(0309118X) 48, no. 2 (July 2020): 12-14, https://search-ebscohost-com.ezproxy.simmons.edu/login.aspx?direct=tr ue\&db=ufh\&AN=145379957\&site=eds-live\&scope $=$ site.

31. Jacek Borecki, “Disinformation as a Threat to Private and State-Owned Businesses," Warsaw Institute (July 25, 2019), https://warsawinstitute.org/disinformation-threat-private-state-owned-businesses/

32. Matthew F. Ferraro and Jason C. Chipman, "Fake News Threatens Our Businesses, Not Just Our Politics," Washington Post (February 8, 2019), https://search-ebscohost-com.ezproxy.simmons.edu/login.aspx?direct=true $\& \mathrm{db}=$ edsgao\&AN=edsgcl.573149015\&site=eds-live\&scope $=$ site.

33. Timothy Hampton, "Fake News and Humanities Education," Berkley News: Berkley Blog (August 9, 2018), https://news.berkeley.edu/berkeley_blog/fake-news-and-humanities-education/.

34. Kirsten Ostherr, "Humanities as Essential Services," Inside Higher Ed (May 21, 2020), https://www.insidehighered.com/views/2020/05/21/how-humanities-can-be-part-front-line-response-pandemic-opinion,

35. Weiss et al., "Surveying Fake News."

36. Weiss et al., "Surveying Fake News," 22.

37. Weiss et al., "Surveying Fake News," 22.

38. Weiss et al., "Surveying Fake News," 24.

39. Boglarka S. Huddleston et al., "Faculty Perspectives on Undergraduate Research Skills: Nine Core Skills for Research Success," Reference \& User Services Quarterly 59, no. 2 (December 22, 2019): 118, https://search-ebscohostcom.ezproxy.simmons.edu/login.aspx?direct=true\&db=edsgao\&AN=edsgcl.619403189\&site=eds-live\&scope=site.

40. Laura Saunders, Information Literacy as a Student Learning Outcome: The Perspective of Institutional Accreditation (Westport, CT: Libraries Unlimited, 2011). 